\section{International Normalized Ratio}

\section{T. Stief}

Institut für Laboratoriumsmedizin und Pathobiochemie, Krankenhaus der Philipps-Universität, Marburg, Deutschland

Synonym(e) Prothrombinzeit-Ratio; INR

Englischer Begriff international normalized ratio; INR

Definition Um die Überwachung der oralen Antikoagulation zu verbessern, wurde von der WHO im Jahr 1983 eine internationale Standardisierung des Quick-Tests ( $\triangleright$ Thromboplastinzeit) vorgenommen und die INR eingeführt. Die INR soll zu einer Verbesserung der Vergleichbarkeit der Messungen mit verschiedenen Thromboplastinen führen.

Beschreibung Die Verwendung verschiedener Thromboplastine, die Kalibrierung an verschiedenen Normalplasmen und Benutzung verschiedener Gerätetypen führen dazu, dass die Ergebnisse des Quick-Tests zwischen den einzelnen Laboren (insbesondere zwischen USA und Europa) nicht übereinstimmen. Die INR bezieht das laboreigene Messergebnis auf einen Standard. Hierzu wird jedem Reagens ein International Sensitivity Index (ISI) zugeordnet, der dessen Empfindlichkeit gegenüber einem Faktorenmangel (Cumarin-induziertem Mangel an > Vitamin K-abhängigen Faktoren) angibt. Der ISI des 1. WHO-Standards beträgt 1,0. An ihm werden alle weiteren WHO-Standards und kommerzielle
Thromboplastine kalibriert. Die meisten kommerziellen Thromboplasten haben heutzutage einen ISI von ca. 1 .

Die INR berechnet sich folgendermaßen:

$$
\mathrm{INR}=[\text { Prothrombinzeit-Ratio }]^{\mathrm{ISI}} \text {, wobei }
$$

Prothrombinzeit-Ratio $=$ Thromboplastinzeit des Patientenplasmas/Thromboplastinzeit des Normalplasmapools

Die ISI eines Thromboplastins wird dadurch bestimmt, dass man die Prothrombinzeit-Ratio von einem Normalplasmapool und Patienten unter oraler Antikoagulation, die man mit diesem Reagenz erhält, gegen die Werte, die man mit dem WHO-Thromboplastin misst, logarithmisch aufträgt. Der ISI ist die Steigung der Kalibrierungsgeraden.

Normalbereich $<1,2$; Zielbereich bei Thrombosen oder Vorhofflimmern 2-3, bei mechanischen Herzklappen 2,5-3,5.

\section{Literatur}

Houdijk WP, Van Den Besselaar AM (2004) International multicenter international sensitivity index (ISI) calibration of a new human tissue factor thromboplastin reagent derived from cultured human cells. J Thromb Haemost 2:266-270

Jackson CM, Esnouf MP (2005) Has the time arrived to replace the quick prothrombin time test for monitoring oral anticoagulant therapy? Clin Chem 51:483-485

Quick AJ, Stanley-Brown M, Bancroft FW (1935) A study of the coagulation defect in hemophilia and in jaundice. Am J Med Sci 190:501 